\title{
Public health insurance in Uganda still only a dream
}

$\mathrm{T}$ hree months ago, Uganda planned to launch a compulsory public health insurance scheme, the first in the country. It didn't happen.

The plan was to initially cover about 2 million employed Ugandans (6\% of the population), including 300000 government workers. Employees would have contributed about $4 \%$ of their gross salary, which employers would match.

It would have been a good start toward universal health coverage, but the National Social Health Insurance Scheme failed to make it through parliament, due to resistance from employers, trade unions and worker representatives. Employers, who already contribute $10 \%$ of employees' gross income to the national pension plan, questioned how the $4 \%$ figure was determined and wondered whether the government could guarantee efficient service delivery, considering the poor state of public health facilities.

Analysts such as Aloysius Ssemanda, former head of the Federation of Uganda Employers, say employers also doubted whether the government could implement such a big program without falling into corruption pitfalls. They cite precedents, including the Global Fund and National Social Security Fund, where officials allegedly misused monies.

Private health care provider Dr. Ian Clarke, the chief executive officer of International Hospital Kampala, argues that the "plan will increase an already stifling tax burden on the public without addressing the underlying problems, especially inefficiency in the current system and slow economic growth," according to the Uganda Health Reporter.

"Health insurance with a legal mandate towards universal coverage is a possibility here, but Uganda is still caught up in skepticism," says Dr. Francis Runumi, the Commissioner for Health Planning at the Ministry of Health.

Despite these hurdles, Uganda, which has a high HIV prevalence rate and several opportunistic re-emerging diseases, including tuberculosis and malaria, is aiming to have mandatory health insurance for all public servants by the end of 2009 and for all Ugandans by 2025.

Uganda is not alone. Most African

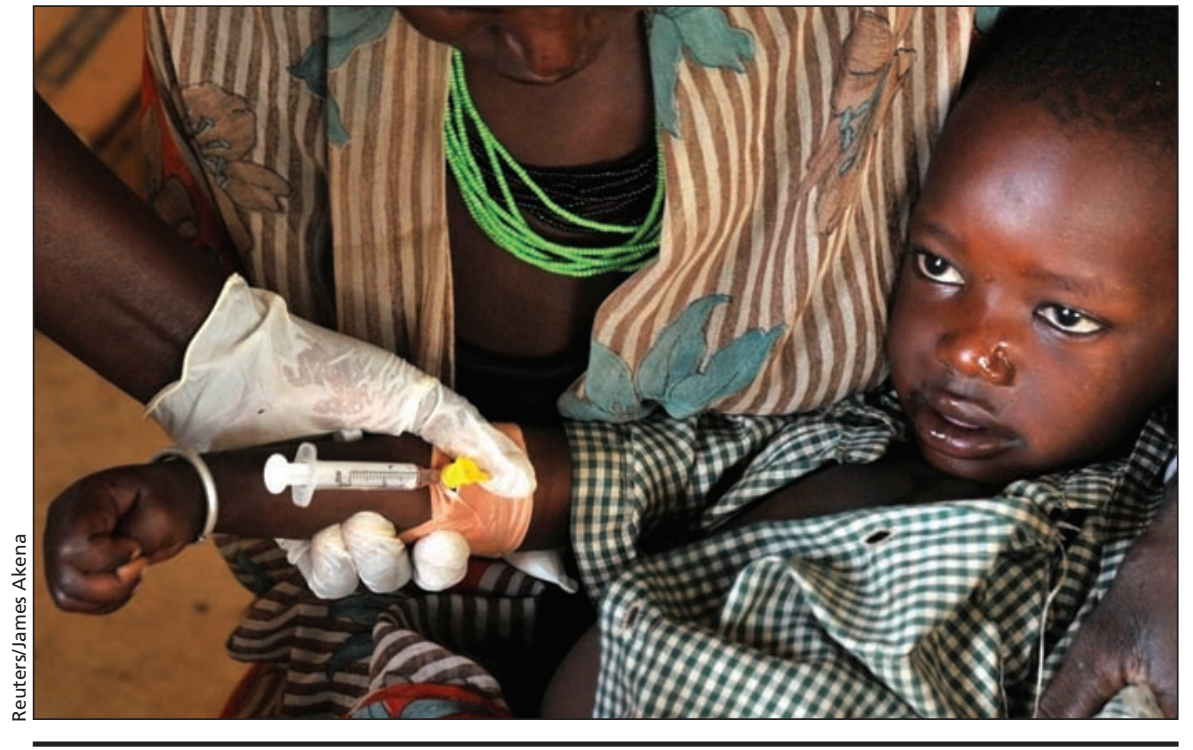

Uganda is aiming to have public health insurance for all public servants by 2009 and for all Ugandans by 2025 . Only about $15 \%$ of Africans now have health insurance.

countries have likewise started to confront the difficulties of health financing. All pledged to realize universal health care by 2015 at the African Union health ministers meeting in Gaborone, Botswana, in 2005

Some African countries have made progress, including Tanzania (5\% coverage, Ghana $(20 \%)$ and Senegal (5\%-10\%). Nigeria started an insurance program in 2005 and now covers about 3 million people. And Rwanda, where the social scheme is comanaged by facilities-community partnerships with promotion from local governments, covers more than $70 \%$ of its population.

But most nations have no nationalized health insurance, so Africans pay out-of-pocket for their health expenses, which are supplemented somewhat by a few free services from government and donor organizations.

Currently, African governments' per capita health expenditure averages \$12-\$15, while aid organizations contribute another \$4-\$5. In the 2001 Abuja Declaration, African countries pledged to allocate $15 \%$ or more of national budgets to health.

Private insurance has been available for about a decade, but only the elite tend to obtain coverage. In Uganda, about 3\% of people have private insurance.

However, there is growth in commu- nity-based health financing schemes, especially in West and Central Africa, where professional groups and some rural and urban communities are creating voluntary, self-managed schemes. Most of these have grown out of traditional risksharing ventures, such as burial societies.

Dr. Richard Alia, a health specialist and World Bank consultant, said that while health insurance is the best way to meet rising health costs, it will take decades for African countries to overcome the challenges. "Developed regions like the United Kingdom and Japan took over 3 decades to perfect their systems, and if Africa realizes this in 30 years, that would be a miracle."

Alia says Africa's rapid population growth, combined with inadequate economic planning, poses a difficulty to health care delivery and affordability.

"Most Africans are too poor to afford premiums and there's too much dependence on aid," says Alia. "If African governments can introduce these schemes with low premiums, this dependency may be broken eventually."

HIV/AIDS has left most African economies stretched, with some dedicating $80 \%$ of health budgets to AIDSrelated health services, - Rosebell Kagumire, Kampala, Uganda

DOI:10.1503/cmaj.082039 